\title{
PENERAPAN FOCAL POINT DI JALAN TOL WIYOTO WIYONO PADA JAKARTA AUTOMOBILE MUSEUM
}

\author{
William Suwono ${ }^{1)}$, Nina Carina ${ }^{2)}$ \\ 1) Program Studi S1 Arsitektur, Fakultas Teknik, Universitas Tarumanagara, williamsuwono9@gmail.com \\ 2) Program Studi S1 Arsitektur, Fakultas Teknik, Universitas Tarumanagara, nincarin@gmail.com
}

\begin{abstract}
Abstrak
Mobil telah menjadi katalis dalam perkembangan pertumbuhan infrastruktur transportasi di Indonesia, sehingga momen bersejarah banyak ditemukan pada perkembangan otomotif di Indonesia. Sampai dengan saat ini, Indonesia belum memiliki museum mobil yang dapat memenuhi hasrat dan aktivitas para penggemar otomotif. Museum Mobil Jakarta menyediakan wadah interaktif bagi masyarakat yang tertarik untuk mempelajari dan memperdalam pengetahuan tentang sejarah otomotif di Indonesia. Konsep dasar dari pembuatan massa bangunan adalah dengan menganalogikan sebuah mobil sport. Pembuatan kaca di bagian depan massa dan serta struktur baja yang di ekspos juga memberikan sebuah identitas bagi bangunan tersebut serta membuat titik fokus pandangan menjadi lebih jelas. Bangunan ini juga ditujukan untuk menjadi ikon dari peninggalan sejarah mobil di Indonesia, dan ikon dari pariwisata Jakarta.
\end{abstract}

Kata kunci: Identitas, Infrastuktur, Museum, Museum Mobil, Titik Fokus

\begin{abstract}
Car has always been a catalyst in transport revolution, and development for physical infrastructure for the people, a lot of Indonesian historic moments are made with cars, yet Indonesian Government has not provided a museum that answers the affection for cars. Jakarta Automobile Museum aimed to be an educative learning hub for people to learn about the history of Indonesian automotive. The main concept of this building are the use of focal point theory and make an analogy from a sports car to make shape of the mass. A Striking front end shape are given to be the focal point and identity for the structure, the glass material and structural steel beams are exposed on front end of the building to give a more robust identity and making the icon of the structure. The building aimed to be an architectural icon for Indonesian Automotive heritage, and an icon in tourism.
\end{abstract}

Keywords: Automobile Museum, Focal Point, Identity, Infrastructure, Museum

\section{PENDAHULUAN}

Sejarah perkembangan mobil dan motor di Indonesia sudah bergerak jauh sejak mobil dan motor pertama di impor ke Indonesia. Mobil dan motor juga memberikan peran penting dalam perkembangan infrastruktur dan ekonomi Indonesia, dengan kata lain mobil dan motor telah menjadi katalis yang mendorong perkembangan Indonesia. Selain menjadi katalis perkembangan dari infrastruktur dan ekonomi Indonesia, mobil dan motor juga merubah pola pikir dan status sosial dari masyarakat Indonesia, mobil dan motor menjadi simbol dari gaya hidup, fashion, dan tolak ukur bagi status sosial seseorang, mobil dan motor menjadi lebih dari sekedar alat transportasi yang menggerakan manusia. Seiring perkembangan jaman, mobil dan motor yang diproduksi menjadi semakin canggih dan memiliki kelas yang beragam untuk menjawab semua kebutuhan setiap tingkat sosial masyarakat Indonesia. Namun ada kelompok masyarakat yang tidak dapat terpuaskan dengan semua kelas mobil dan motor yang beredar di pasar, kelompok masyarakat yang memiliki kecintaan terhadap perkembangan otomotif di Indonesia, kelompok masyarakat ini menginginkan mobil dan motor yang memiliki nilai lebih dari sekedar merek, model atau teknologi yang canggih, kelompok masyarakat ini menginginkan kendaraan dengan nilai sejarah yang tinggi dan tingkat kelangkaan yang luar 
biasa, mobil dan motor ini tidak mudah dicari dan didapatkan, sehingga dibutuhkan wadah yang dapat menampung semua informasi dan ketersediaannya.

Perkembangan mobil dan motor di Indonesia berkembang sangat pesat, mobil dan motor baru diluncurkan hampir setiap 2-3 bulan sekali, ATPM (Agen Tunggal Pemegang Merek) selalu berlomba-lomba untuk meluncurkan model dan kelas baru untuk merebut image pasar terhadap brand yang mereka jual. Namun sejarah mobil dan motor yang ada di Indonesia seperti ditinggalkan dan tidak memiliki apresiasi yang menjadikan hal tersebut sesuatu yang spesial, walaupun banyaknya peminat yang menginginkan mobil dan motor klasik ini, kurangnya informasi dan wadah bagi mereka untuk melakukan pencarian model dan tahun yang diminati mengurangi minat banyak antusias mobil klasik. Informasi tentang keberadaan mobil dan motor klasik hanya sebatas mulut ke mulut. Selain antusias, pemilik koleksi juga kadang tidak memiliki wadah bagi mereka untuk menjual koleksi mereka, beberapa bahkan tidak memiliki dana untuk merawat koleksi mereka sehingga banyak koleksi mobil mereka berujung menjadi bangkai. Kumpulan mobil dan motor klasik yang ada di Indonesia dapat dikumpulkan ke dalam suatu pelelangan yang bersifat eksebisi, lelang akan dilakukan terbuka sehingga masyarakat publik dapat melihat dan mempelajari nilai sejarah dari mobil atau motor yang akan di lelang. Di satu sisi mobil dan motor yang dilelang ini kemudian dapat menjadi pertunjukkan bagi publik dengan nilai sejarah dan kebudayaan yang disandang, di sisi lain sebuah museum dapat menjadi sumber edukasi bagi masyarakat seiring menambah nilai investasi dari barang tersebut.

\section{METODE}

Metode perancangan yang digunakan berupa pendekatan deduktif melalui literatur buku terutama buku 'Architecture Tourism' oleh Jan Specht. Selain itu survey lapangan dilakukan terhadap tapak yang sudah ada, serta kondisi kawasan di sekitar tapak. Metode selanjutnya adalah analisis kebutuhan ruang berdasarkan standar kebutuhan museum mobil.

\section{DISKUSI DAN HASIL}

Konsep museum yang terletak di Jalan Yos Sudarso ini adalah untuk menjadi pusat otomotif di daerah Sunter, pergerakan pengunjung yang paling banyak terjadi datang dari Jalan tol Wiyoto Wiyono yang terletak di depan tapak, sehingga penting bagi proyek ini agar bisa memberikan sebuah fitur yang menonjol dari sudut pandang Jalan Layang tersebut. Bentuk massa yang dibuat berupa sebuah cantilever yang memberikan identitas bagi pada bangunan tersebut dan juga sekaligus memberikan focal point ${ }^{1)}$ bagi pandangan dari level tol Wiyoto Wiyono, sehingga penting bagi bangunan agar memberikan sebuah fitur penting dari cantilever tersebut.

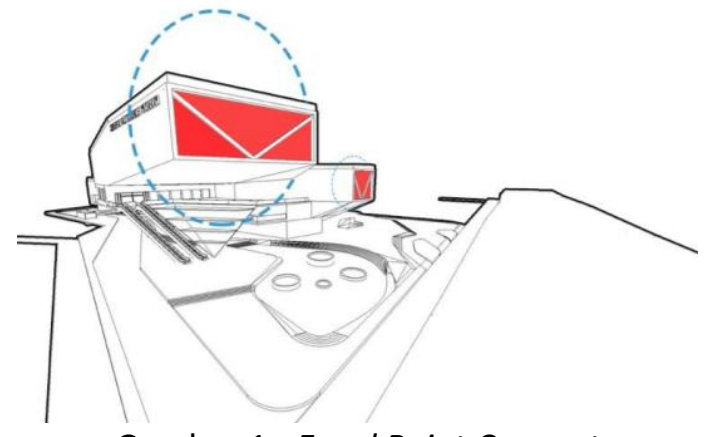

Gambar 1. Focal Point Concept

Sumber: Dokumentasi Pribadi, 2018

\footnotetext{
${ }^{1)} A$ focal point is a design feature that makes an architectural experience meaningful. As an architectural element, it provides a goal for our explorations. It acts as a reason for our investigation of form and space. It anchors architectural composition. A focal point may incorporate symbolism, as with an altar in a church or a
} 
fireplace that attracts the company of friends and family. Or it may simply be an abstract emphasis within the total spatial experience. The center of interest is not always the literal geometric center of a work of art. It is the point where the weight of the work is concentrated. It is the visual center of gravity. It is the area that your attention naturally settles upon. Venus happens to be the geometric center of her painting, but in Argenteuil by Claude Monet (1840-1926) the focal point is well offcenter: the building at the end of the road.

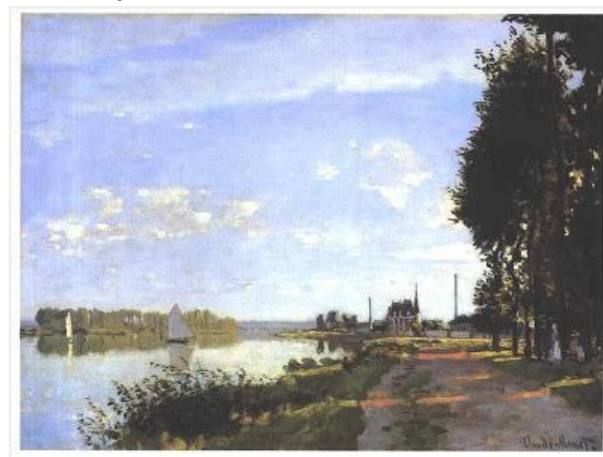

Gambar 2. Argentuil oleh Claude Monet Sumber: Michael Knorr Archive - Michaelknorrarchitecture.com

It is a focal point because every other element in the composition gestures towards it: the bold line of the horizon, the edges of road and water, the angle of trees as they diminish in perspective. Despite being off-center, the location of the focal point is undeniable and easily diagrammed.

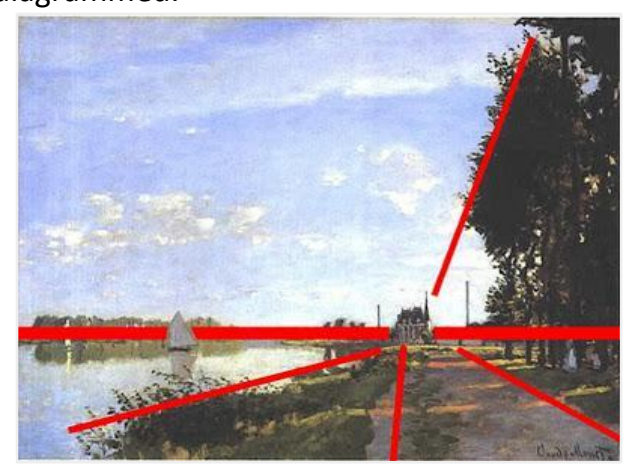

Gambar 3. Argentuil oleh Claude Monet

Sumber: Michael Knorr Archive - Michaelknorrarchitecture.com

The focal point of a design or image is the main thing that you want the viewer to see or understand. Everything else becomes a supporting character visually. You can create more than one focal point in a design and, depending on what your intention is, those focal points can either compete with each other or one can be greater in importance and the other secondary. It's all in what your purpose is - what you're trying to communicate. What l've included below are five of the methods for creating a focal point. These are fairly simple and should be obvious as you look at the examples.' Focal Points - Michael Knorr

Bagian depan dari massa dibuat untuk menarik perhatian pengunjung yang datang dari level jalan tol. Pemilihan material kaca dan struktur baja yang di ekspos menambah identitas bangunan sehingga memberikan daya tarik tersendiri. Bangunan dibuat untuk menjadi pusat perhatian, karena selain menjadi ikon bagi pariwisata Jakarta, bangunan ini juga menjadi ikon bagi kekuatan perkembangan otomotif Indonesia, serta ikon otomotif bagi kota Jakarta Utara. 


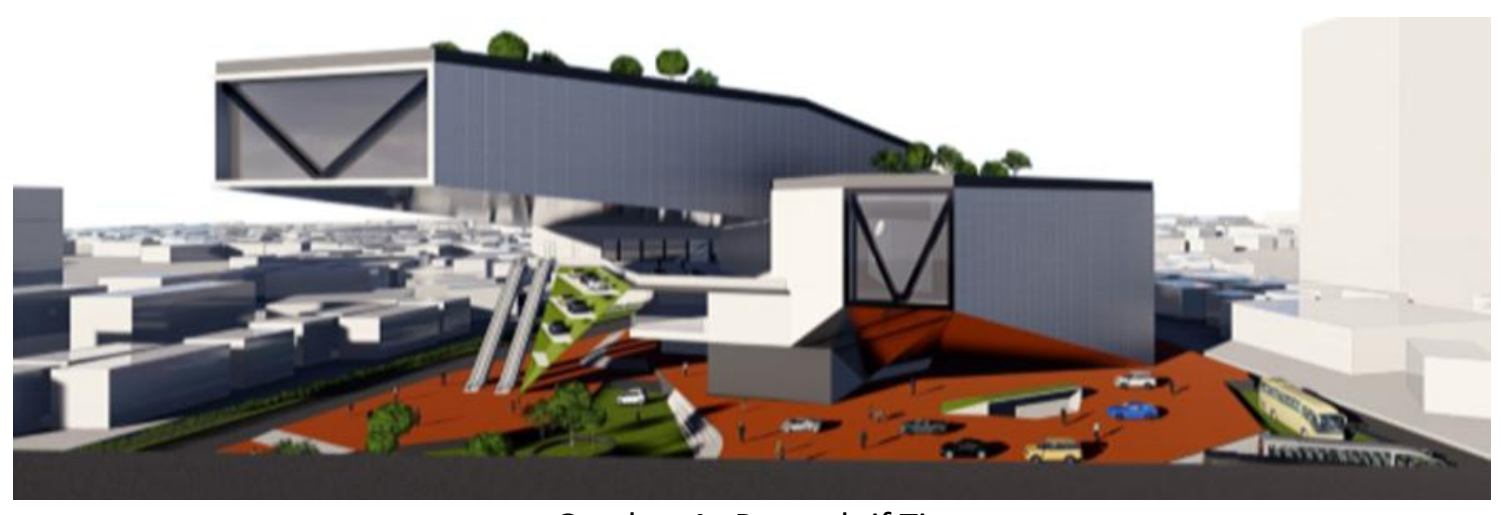

Gambar 4. Perspektif Timur

Sumber: Dokumentasi Pribadi, 2018

Material yang dipilih merupakan kombinasi dari beberapa material seperti cermin, composite panel, dan baja yang di ekspos. Cermin dipilih pada bagian ruang maya agar menimbulkan kesan reflektif dan ketidakterbatasan dari ruang tersebut sehingga pengunjung bisa merasakan di ruang yang jauh lebih besar dari ruang sebenarnya. composite panel dipilih karena pemasangannya yang mudah, materialnya yang versatile dan mudah dibersihkan. Baja ekspos dipilih untuk memberikan identitas dan bentuk pada bangunan yang menjadi ikon bangunan tersebut. Ruang maya yang berada di bawah massa bangunan dibuat untuk acaraacara outdoor dan juga museum outdoor temporer. Hal ini juga memberikan kesan seamless antara ruang luar dan ruang dalam, sehingga memberikan pengalaman ruang dalam yang berbeda. hal ini ditunjukkan dengan pembuatan sky lobby yang ada di lantai 3 dari bangunan, dimana aktivitas utama bangunan dimulai dari lobby outdoor yang terletak di lantai tiga, namun dengan adanya ruang maya ini pengalaman ruang yang dirasakan terasa seperti di dalam ruang tertutup.

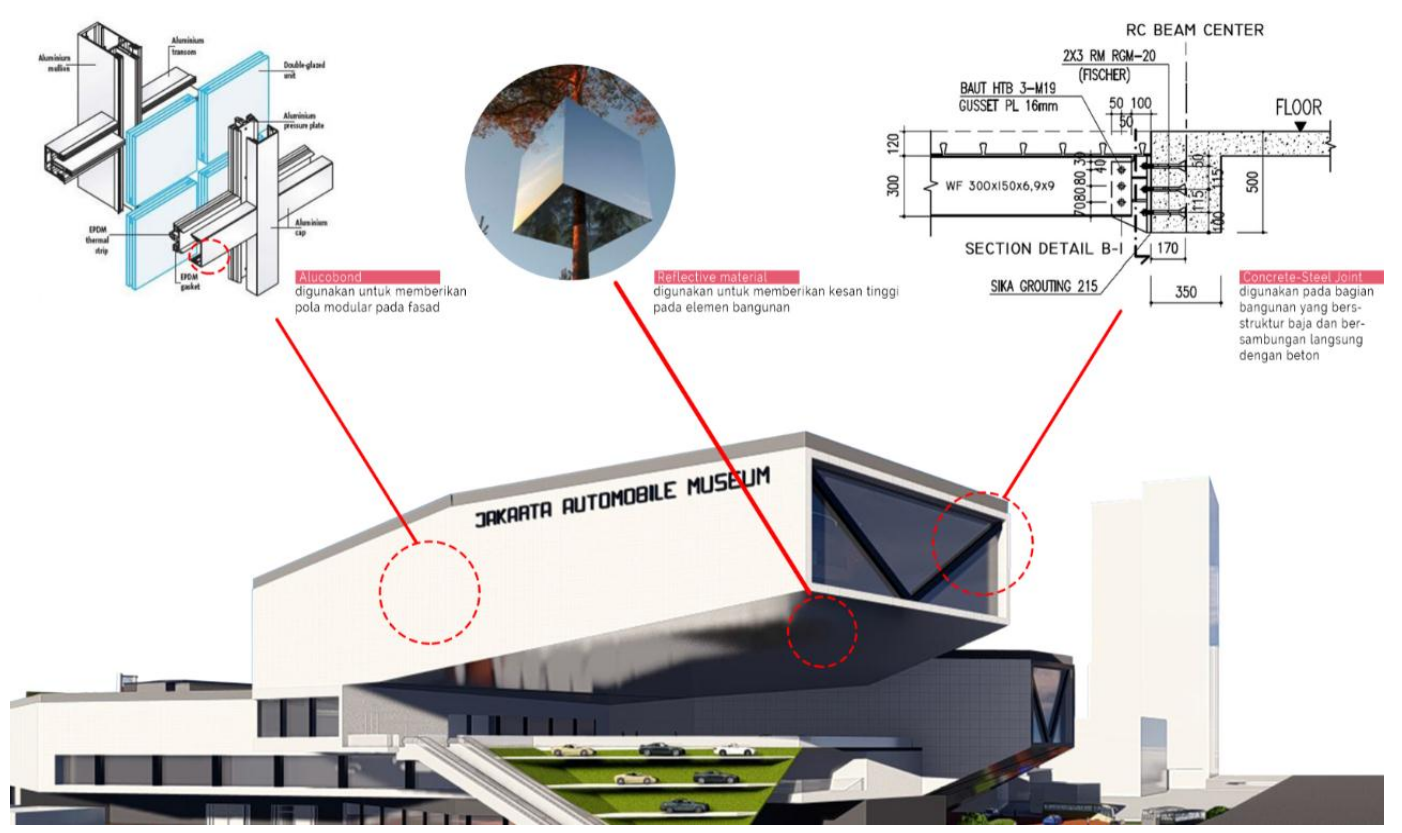

Gambar 5. Detail Material

Sumber: Dokumentasi Pribadi, 2018

\section{KESIMPULAN DAN SARAN}

Focal Point menjadi poin utama dalam konsep desain bangunan museum ini, permainan material dan bentuk massa menjadi penyelesaian desain untuk bangunan ini. Museum mobil yang ditujukan untuk menjadi pusat dan ikon otomotif dari kota Jakarta Utara serta menjadi 
ikon pariwisata dari kota Jakarta, di desain untuk menarik perharian dengan penyelesaian desain yang unik dan menarik perhatian baik bagi turis lokal maupun mancanegara, dengan melakukan pemilihan dan bentuk massa yang memberikan focal point bagi desain perkotaan.
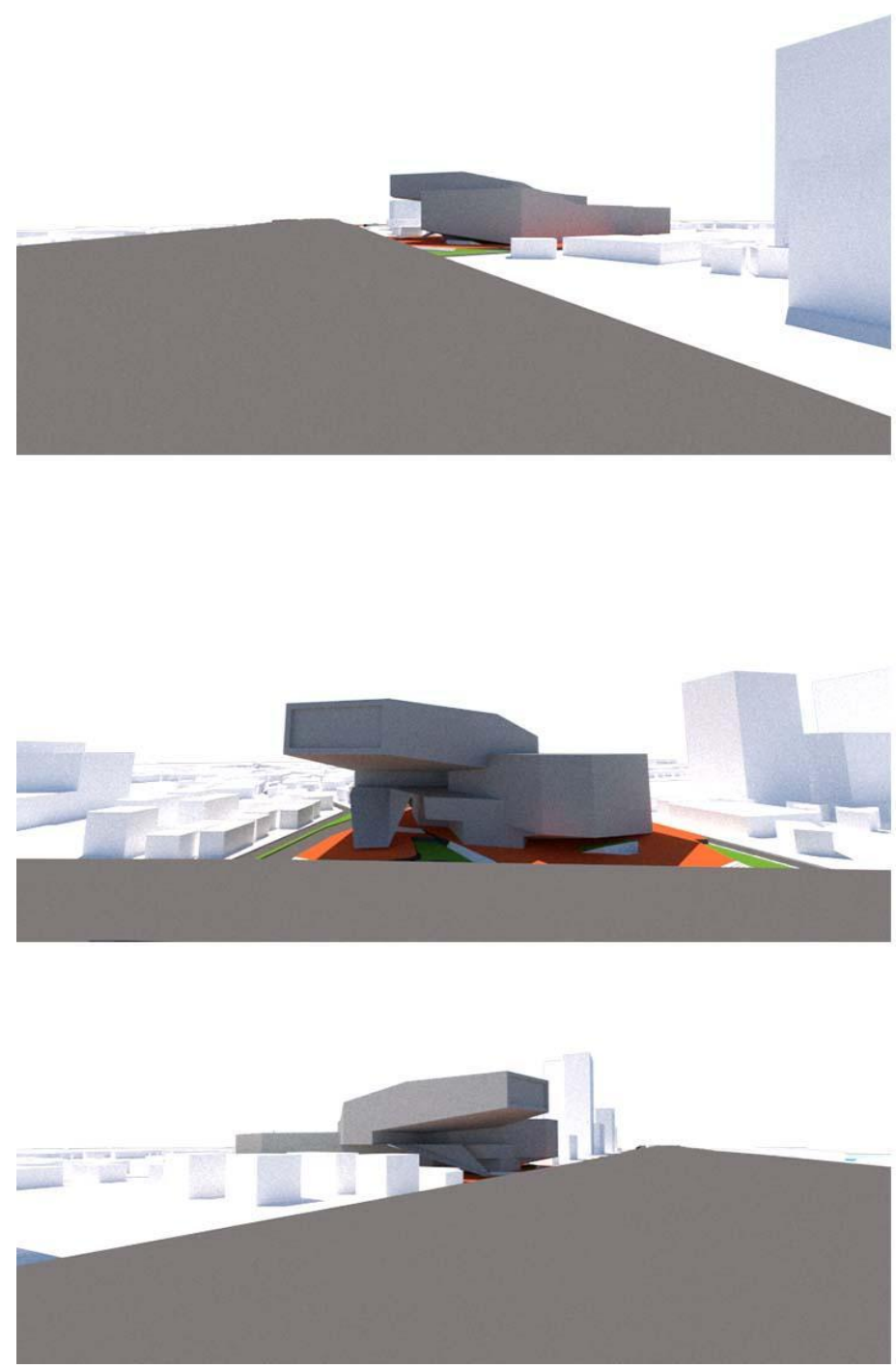

Gambar 6. View Dari Jalan Tol

Sumber: Dokumentasi Pribadi, 2018

\section{UCAPAN TERIMA KASIH}

Puji dan syukur kepada Tuhan Yang Maha Esa atas segala rahmat dan berkat yang telah diberikan Nya sehingga penulis dapat menyelesaikan tulisan ini. Penulis mengucapkan terima kasih kepada seluruh dosen dan pembimbing di Fakultas Teknik Universitas Tarumanagara dan orang tua penulis yang tidak henti mendorong terutama secara moral sehingga dapat memberikan motivasi kepada penulis untuk memberikan karya yang terbaik serta seluruh kerabat, teman, dan narasumber yang mendukung terciptanya karya ini.

Sebagai penutup penulis menyadari bahwa laporan ini masih memiliki kekurangan, namun penulis berharap semoga karya ini dapat bermanfaat dan memberikan dampak positif bagi seluruh pihak.

\section{REFERENSI}

Specht, Jan. (2014). Architectural Tourism, Munich: Springer Gabler.

Tjahyono, Gunawan. Metode Perancangan Suatu Pengantar untuk Arsitek dan Perancangan.

Jakarta: UI. 999. 
W. Mcintosh, R. (1990). Tourism: Principles, Practices, Philosophies. New York: John Wiley \& Sons, Inc.

Focal Point, diunduh 16 Januari 2019, http://www.michaelknorrarchitecture.com/ 5 Way to Create focal point, https://alvalyn.com/5-ways-to-create-a-focal-point/ 